\title{
Three regimens of procaine penicillin G, Augmentin, and probenecid compared for treating acute gonorrhoea in men
}

\author{
K B LIM, T THIRUMOORTHY, C T LEE, E H SNG, AND T TAN \\ From the Middle Road Hospital, Singapore
}

SUMMARY The efficacy of three penicillin regimens in treating uncomplicated gonorrhoea in men was evaluated. The regimens consisted of: (1) Augmentin $3.25 \mathrm{~g}$ plus probenecid $1 \mathrm{~g}$ orally; (2) aqueous procaine penicillin G $4.5 \mathrm{MIU}$ intramuscularly and probenecid $1 \mathrm{~g}$ plus one tablet of Augmentin $375 \mathrm{mg}$ orally; or (3) aqueous procaine penicillin G $4.5 \mathrm{MIU}$ intramuscularly and probenecid $1 \mathrm{~g}$ plus two tablets of Augmentin $375 \mathrm{mg}$ orally. Cure rates for infections caused by penicillinase ( $($ lactamase) producing Neisseria gonorrhoeae (PPNG) were $87 \%$ (20/23) for regimen 1 , $97 \%(28 / 29)$ for regimen 2 , and $95 \%(19 / 20)$ for regimen 3 . Thus the addition of one or two tablets of

- Augmentin $375 \mathrm{mg}$ to aqueous procaine penicillin $\mathrm{G}$ and probenecid cured $96 \%$ (47/49) of infections caused by PPNG strains. All three regimens were $100 \%$ effective in eradicating infections caused by non-PPNG strains. Post gonococcal urethritis occurred in $24 \%$ of cases treated with regimen 1, $14 \%$ of cases treated with regimen 2 , and $15 \%$ of cases treated with regimen 3 . The geometric minimum inhibitory concentrations $\left(\mathrm{MIC}_{90}\right)$ of Augmentin for 72 PPNG and 162 non-PPNG isolates of $N$ gonorrhoeae obtained before treatment were 1.98 and $0.55 \mathrm{mg} / 1$, respectively. Regimen 2 , besides being effective against infections caused by PPNG or non-PPNG strains, has the advantage of cost effectiveness and low toxicity. This regimen may be useful in treating gonorrhoea in areas of high prevalence of PPNG strains, such as South East Asia and Africa.

\section{Introduction}

The prevalence of infection with penicillinase ( $B$ lactamase) producing strains of Neisseria gonorrhoeae (PPNG), which is $35-60 \%$ in South East Asia, precludes the routine use of penicillins in the treatment of gonorrhoea. ${ }^{1}$ Though new antimicrobial agents are effective, their usefulness is sometimes limited by toxicity or cost. Another major consideration is that discontinuation of using penicillins may lead to a resurgence of early syphilis. In at least one country in this region, namely Singapore, there has been a steady increase in the incidence of early syphilis in the past four years. This seemed to coincide with the gradual discontinuation, from 1980 , of penicillin treatment in favour of drugs that are effective against PPNG strains but non-treponemicidal. ${ }^{2}$ Though other factors, such as a decrease in herd immunity, may be responsible, a return to conventional penicillin treatment is clearly

Address for reprints: Dr K B Lim, Middle Road Hospital, 250 Middle Road, Singapore 0718, Republic of Singapore

Accepted for publication 21 August 1985 desirable for several reasons, including the known effectiveness of penicillin in aborting incubating syphilis. $^{3}$

A major advance in treatment came with the introduction of clavulanic acid, a potent inhibitor of $B$ lactamase. ${ }^{4}$ This agent is available in combination with amoxycillin as Augmentin tablets $375 \mathrm{mg}$ (amoxycillin $250 \mathrm{mg}$ plus clavulanic acid $125 \mathrm{mg}$ ). Earlier (unpublished) studies conducted in this hospital using a single $3.25 \mathrm{~g}$ dose of Augmentin (amoxycillin $3 \mathrm{~g}$ and clavulanic acid $250 \mathrm{mg}$ ) in powder form produced cure rates of $71 \%$ and $92 \%$ respectively for infections caused by PPNG and non-PPNG strains. In a subsequent study the same dose was repeated four hours later and we obtained enhanced cure rates of $96.6 \%$ and $95.6 \%$, respectively. ${ }^{5} \mathrm{We}$ postulated at the time that the poor results obtained with single dose treatment of PPNG infections, compared with non-PPNG infections, was due to the short duration of effective concentrations of clavulanic acid present in body fluids. A recent study from Nairobi, Kenya, however, suggests that it is the duration of effective amoxycillin concentrations that 
is essential to the success of treatment. These workers found cure rates of $96 \%$ for infections caused by PPNG strains treated with Augmentin $3.25 \mathrm{~g}$ plus probenecid $1 \mathrm{~g}$, and also reported $98 \%$ cure rates when they added one tablet of Augmentin $375 \mathrm{mg}$ (amoxycillin $250 \mathrm{mg}$ and clavulanic acid $125 \mathrm{mg}$ ) to aqueous procaine penicillin G 4.8 MIU plus probenecid $1 \mathrm{~g}$ (D'Costa LJ et al, unpublished observation).

In the study published here, therefore, we attempted to confirm these results using three penicillin regimens consisting of: (1) Augmentin $3.25 \mathrm{~g}$ (amoxycillin $3 \mathrm{~g}$ and clavulanic acid $250 \mathrm{mg}$ ) plus probenecid $1 \mathrm{~g}$ orally; (2) aqueous procaine penicillin G 4.5 MIU intramuscularly and probenecid $1 \mathrm{~g}$ plus Augmentin $375 \mathrm{mg}$ (amoxycillin $250 \mathrm{mg}$ and clavulanic acid 125 $\mathrm{mg}$ ) orally; and (3) aqueous procaine penicillin $\mathrm{G} 4.5$ MIU intramuscularly and probenecid $1 \mathrm{~g}$ plus two tablets of Augmentin $375 \mathrm{mg}$ orally. We used $4.5 \mathrm{MIU}$ of aqueous procaine penicillin $\mathrm{G}$, as this was available in 3 MIU ampoules and reconstituting 4.5 MIU was simple.

\section{Patients and method}

\section{STUDY POPULATION}

We conducted the study at the outpatient department of this hospital between 15 August and 31 December 1984. We studied 266 men aged 18 years and over whose urethral smears showed intracellular Gram negative diplococci. All these diagnoses of gonorrhoea were confirmed by subsequent culture. We excluded patients with histories of allergy to penicillin and those who had received antimicrobial agents within the preceding 72 hours.

\section{CULTURE OF N GONORRHOEAE}

All urethral specimens obtained with sterile platinum loops were immediately inoculated into modified Thayer-Martin medium, incubated at $36^{\circ} \mathrm{C}$ in an atmosphere of carbon dioxide, and examined after 24 to 48 hours. Gonococcal isolates were recognised by their colonial morphology, oxidase reaction, and Gram stained appearance on microscopy. Penicillinase production was tested by the paper acidometric method described previously. ${ }^{6}$ Confirmed isolates were tested for antibiotic susceptibility to Augmentin by the agar plate dilution method. ${ }^{7}$ We used Augmentin (amoxycillin and clavulanic acid in a ratio of $2: 1$ ) in doubling dilutions from $8 \mathrm{mg} / 1$ to 0.125 $\mathrm{mg} / \mathrm{l}$.

\section{TREATMENT REGIMENS}

Three penicillin regimens were used: regimen 1 consisted of Augmentin $3 \cdot 25 \mathrm{~g}$ (amoxycillin $3 \mathrm{~g}$ and clavulanic acid $250 \mathrm{mg}$ ) plus probenecid $1 \mathrm{~g}$ orally; regimen 2 consisted of aqueous procaine penicillin $G$
4.5 MIU intramuscularly and probenecid $1 \mathrm{~g}$ plus one tablet of Augmentin $375 \mathrm{mg}$ (amoxycillin $250 \mathrm{mg}$ and clavulanic acid $125 \mathrm{mg}$ ) orally; and regimen 3 consisted of aqueous procaine penicillin G 4.5 MIU intramuscularly and probenecid $1 \mathrm{~g}$ plus two tablets of Augmentin $375 \mathrm{mg}$.

The study of 266 men was conducted in two phases. In the first phase, conducted between 15 August and 18 November 1984 , we randomly allocated 189 men to one of the three penicillin regimens. In the second phase, conducted between 19 November and 31 December 1984, we randomly allocated 77 men to regimens 1 or 2 only, as excellent results were already being recorded with regimen 2. Augmentin powder 3.25g (formulated by Beecham Pharmaceuticals, England) was dissolved in a glass of water and administered to the patients under supervision. All patients treated with intramuscular aqueous procaine penicillin $G$ were observed for the recommended half hour after treatment.

\section{FOLLOW UP AND TESTS OF CURE}

All patients were scheduled to return three to five days and 10 to 20 days after treatment. Cure was defined by the absence of gonococci in urethral smears and negative culture results 72 hours or more after treatment. If gonococci persisted or reappeared within 20 days after treatment and sexual intercourse had not taken place treatment was considered to have failed. The reappearance of gonococci at the second follow up visit was considered to be due to reinfection only if sexual intercourse had taken place. Patients who had had sexual intercourse before the first follow up visit and those who had vomited within two hours of taking medication were excluded from analysis of efficacy.

Patients who were followed up for 10 or more days were evaluated for postgonococcal urethritis (PGU). PGU was diagnosed if five or more polymorphonuclear leucocytes per $1000 \times$ microscope field were present without Gram negative diplococci and $N$ gonorrhoeae was not found on culture. Patients who had had sexual intercourse before the second follow up visit, or who had received antimicrobial agents for other conditions, were excluded from analysis for PGU. All patients who attended at least one follow up visit were evaluated for side effects of treatment. The Venereal Disease Research Laboratory (VDRL) test was routinely performed before treatment and six weeks and three months after treatment.

\section{Results}

\section{STUDY POPULATION}

Of 266 men selected for the study, 30 were excluded; four because of re-exposure before the first follow up visit, two because of other conditions requiring 
TABLE I Number (\%) of patients with gonorrhoea cured by each of three penicillin regimens

\begin{tabular}{lllll}
\hline & & \multicolumn{2}{l}{ Strains } & \\
\cline { 3 - 4 } Regimen & PPNG & Non-PPNG & Total (\%) \\
\hline 1 & No assessed & 23 & 67 & 90 \\
2 & No (\%) cured & $20(87)$ & $67(100)$ & $87(97)$ \\
2 & No assessed & 29 & 59 & 88 \\
& No (\%) cured & $28(97)$ & $59(100)$ & $87(99)$ \\
3 & No assessed & 20 & 38 & 58 \\
& No (\%) cured & $19(95)$ & $38(100)$ & $57(98)$ \\
\hline
\end{tabular}

Regimen $1=$ Augmentin $3.25 \mathrm{~g}$ plus probenecid $1 \mathrm{~g}$ orally;

Regimen 2 = aqueous procaine penicillin G 4.5 MIU intramuscularly and probenecid $1 \mathrm{~g}$ plus Augmentin $375 \mathrm{mg}$ orally;

Regimen $3=$ aqueous procaine penicillin G 4.5 MIU intramuscularly and probenecid $1 \mathrm{~g}$ plus Augmentin $750 \mathrm{mg}$ orally.

treatment (one with early latent syphilis and one with chancroid), four because of vomiting all the medicine, and 20 because they defaulted after treatment. There remained for evaluation, therefore, 236 patients; 90 were treated with regimen 1,88 treated with regimen 2 , and 58 treated with regimen 3 . The ages of the patients ranged from 18 to 56 (mean 24.6) years.

\section{ERADICATION OF $N$ GONORRHOEAE}

Table I shows the results of treatment. Of 90 patients treated with regimen $1,87(97 \%)$ were cured compared with $87(99 \%)$ of 88 patients treated with regimen 2 and $57(98 \%)$ of 58 patients treated with regimen 3 . Of patients with infections caused by PPNG strains, 20 $(87 \%)$ of 23 treated with regimen 1 were cured compared with $28(97 \%)$ of 29 patients treated with regimen 2 and $19(95 \%)$ of 20 patients treated with regimen 3. All regimens were $100 \%$ effective in treating a total of 164 infections caused by non-PPNG strains. Aqueous procaine penicillin G 4.5 MIU intramuscularly and probenecid $1 \mathrm{~g}$ plus one or two tablets of Augmentin $375 \mathrm{mg}$ therefore cured $96 \%$ (47/49) of infections caused by PPNG strains and $100 \%$ of infections caused by non-PPNG strains, giving an overall cure rate of $99 \%$ (144/146).

\section{OCCURRENCE OF PGU}

Of the 214 pateints evaluated for PGU, $19(24 \%)$ of 78 patients treated with regimen $1,12(14 \%)$ of 83 patients treated with regimen 2 , and eight $(15 \%)$ of 53 patients treated with regimen 3 developed this complication. The combined rate of $\mathrm{PGU}$ for regimens 2 and 3 was $15 \%$. The differences between all three treatment groups failed to reach significance (p>0.05).

\section{TOLERANCE}

We evaluated 245 patients for side effects of treatment. As expected, local pain of variable severity was experienced by most patients receiving regimens 2 or 3 because of the intramuscular injection of aqueous procaine penicillin $G$. Table II shows other side effects experienced by patients. Thus, eight $(8 \%)$ of 95
TABLE II Side effects of treatment with each of three penicillin regimens

\begin{tabular}{llll}
\hline Regimen & Side effects & $\begin{array}{l}\text { No of } \\
\text { patients } \\
\text { affected }\end{array}$ & $\begin{array}{l}\text { Total (\%) } \\
\text { affected }\end{array}$ \\
\hline $1(n=95)$ & $\begin{array}{l}\text { Vomiting } \\
\text { Nausea } \\
\text { Diarrhoea }\end{array}$ & 5 & \\
& Rash & 1 & \\
$2(n=90)$ & Vomiting & 3 & $8(8)$ \\
& Rash & 2 & \\
$3(n=60)$ & Procaine reaction & 1 & $6(7)$ \\
& $\begin{array}{l}\text { Vomiting } \\
\text { Nausea } \\
\text { Nausea and } \\
\text { giddiness }\end{array}$ & 7 & \\
& Procaine reaction & 1 & \\
& & 1 & $10(17)$ \\
& & 1 &
\end{tabular}

For definition of regimens see table $\mathrm{I}$.

patients treated with regimen 1 , six $(7 \%)$ of 90 patients treated with regimen 2 , and $10(17 \%)$ of 60 patients treated with regimen 3 experienced these side effects. It is noteworthy that four patients (three treated with regimen 1 , and one treated with regimen 3 ) vomited within two hours of taking the medication and had to be excluded from efficacy analysis because of the possibility of inadequate drug absorption. Regimen 2 appeared to be well tolerated and had the lowest incidence $(7 \%)$ of side effects. The amount of clavulanic acid in regimen 2 was $125 \mathrm{mg}$ compared with $250 \mathrm{mg}$ in regimens one and three, which suggests that the higher dose of clavulanic acid may be associated with more gastrointestinal side effects. Nevertheless all side effects were transient, and affected patients recovered fully after a period of observation or simple treatment with topical steriods and antihistamines, without any need for admission to hospital.

\section{ANTIBIOTIC SUSCEPTIBILITY TESTING}

Table III shows the results of antibiotic susceptibility testing. The mean $\mathrm{MIC}_{90}$ was $1.98 \mathrm{mg} / 1$ for PPNG strains and $0.55 \mathrm{mg} / 1$ for non-PPNG strains.

TABLE III Number of strains of Neisseria gonorrhoeae inhibited by various concentrations of Augmentin

\begin{tabular}{lrrrrr}
\hline & \multicolumn{4}{l}{$\begin{array}{l}\text { Geometric minimum inhibitory } \\
\text { concentrations }\left(M I C_{90}\right)\end{array}$} \\
\cline { 2 - 6 } Strains & 0.25 & 0.5 & 1.0 & $2 \cdot 0$ & $4 \cdot 0$ \\
\hline PPNG $(\mathrm{n}=72)^{*}$ & & 1 & 17 & 36 & 18 \\
Non-PPNG $(\mathrm{n}=162)^{*}$ & 56 & 48 & 40 & 17 & 1
\end{tabular}

* Two isolates were not retrieved from stock cultures for MIC assessment. 


\section{Discussion}

Augmentin $3.25 \mathrm{~g}$ plus probenecid $1 \mathrm{~g}$ orally cured $87 \%$ of PPNG and $100 \%$ of non-PPNG infections, giving an overall success rate of $97 \%$. Thus the addition of probenecid $1 \mathrm{~g}$ greatly improved the cure rates of $71 \%$ for PPNG and $92 \%$ for non-PPNG infections that had been obtained in an earlier (unpublished) study using Augmentin $3.25 \mathrm{~g}$ alone. More remarkably, the addition of one or two tablets of Augmentin $375 \mathrm{mg}$ to aqueous procaine penicillin G and probenecid resulted in excellent cure rates of $96 \%$ for PPNG infections and $100 \%$ for non-PPNG infections. Thus these results show that one tablet of Augmentin $375 \mathrm{mg}$ contained sufficient clavulanic acid $(125 \mathrm{mg})$ to inactivate $B$ lactamase and that it is the duration of effective penicillin concentrations that is important. Our results also show that higher dosts of clavulanic acid are unnecessary and may be associated with more gastrointestinal side effects.

All three regimens were ineffective in preventing PGU, though a lower PGU rate was associated with regimens $2(14 \%)$ and $3(15 \%)$ compared with regimen 1.

We conclude that intramuscular aqueous procaine penicillin G 4.5 MIU and probenecid $1 \mathrm{~g}$ plus one tablet of Augmentin $375 \mathrm{mg}$ is efficacious treatment against both PPNG and non-PPNG strains. This treatment is associated with low toxicity and low cost as well as being effective against incubating syphilis, ${ }^{3}$ and should be considered for treating gonorrhoea in areas of high prevalence of PPNG strains, such as the Far East and Africa. The efficacy of this regimen in treating pharyngeal and rectal gonorrhoea due to PPNG strains should also be evaluated.

We thank Dr OPW Robinson, Medical Director, Beecham Pharmaceuticals International Division, for providing Augmentin for this study.

\section{References}

1 Centers for Diseases Control. Global distribution of penicillinase producing Neisseria gonorrhoeae (PPNG). MMWR 1982;31:1-3.

2 Giam YC Recent trends in sexually transmitted diseases. Epidemiological News Bulletin, Singapore 1984;X:39-42.

3 Schroeter AL, Turner RH, Lucas JB, Brown WJ. Therapy for incubating syphilis: effectiveness of gonorrhea treatment. JAMA 1971;218:711-3.

4 Miller JM, Baker CN, Thornsberry C. Inhibition of betalactamase in Neisseria gonorrhoeae by sodium clavulanate. Antimicrob Agents Chemother 1978;14:794-6.

$5 \quad$ Lim KB, Rajan VS, Giam YC, Lui EO, Sng EH, Yeo KL. Two dose Augmentin treatment of acute gonorrhoea in men. British Journal of Veneral Diseases 1984;60:161-3.

6 Sng EH, Yeo KL, Rajan VS. Simple method of detecting penicillinase-producing Neisseria gonorrhoeae and Staphylococcus aureus. British Journal of Venereal Diseases 1981;57:141-2.

7 Sng EH, Rajan VS, Pang R, Yeo KL. Susceptibility of Neisseria gonorrhoeae to cefotaxime and ceftizoxime. British Journal of Venereal Diseases 1981;57:162-4. 